\title{
Desenvolvimento inicial de Urochloa ruziziensis e desempenho agronômico da soja em diferentes arranjos espaciais no cerrado Mato-Grossense
}

\author{
Willian Batista Silva ( $)$; Fabiano André Petter (2*); Larissa Borges de Lima (3); Fabricio Ribeiro Andrade ( ${ }^{4}$ ) \\ (1) Universidade Estadual do Norte Fluminense “Darcy Ribeiro” (UENF), Programa de Pós-graduação em Produção Vegetal, $28013-602$ \\ Campos dos Goytacazes (RJ), Brasil. \\ (2) Universidade Federal de Mato Grosso (UFMT), Departamento de Fitotecnia, 78557-267 Sinop (MT), Brasil. \\ (3) Universidade Federal de Goiás (UFG), Programa de Pós-graduação em Agronomia -Solo e Água, 74001-970 Goiânia (GO), Brasil. \\ (4) Universidade Federal de Lavras (UFLA), Programa de Pós-graduação em Ciência do Solo, 37200-000 Lavras (MG), Brasil. \\ $\left(^{*}\right)$ Autor correspondente: petter@ufmt.br
}

Recebido: 22/mar./2013; Aceito: 13/jun./2013

\section{Resumo}

A consolidação do sistema de plantio direto no cerrado ainda encontra dificuldades quanto ao estabelecimento das plantas de cobertura. Nesse sentido, tem se optado pela técnica da sobressemeadura visando o aproveitamento da umidade no fim do período chuvoso. Entretanto, nem sempre há sucesso no estabelecimento das culturas com esse sistema de semeadura. Dessa forma, objetivou-se com este trabalho avaliar o desenvolvimento inicial de Urochloa ruziziensis em sobressemeadura no estágio R5.3 e desempenho agronômico da soja sob diferentes espaçamentos nas entrelinhas de cultivo. O trabalho foi conduzido a campo em Barra do Garças (MT) Brasil, na safra 2010/2011. O delineamento experimental foi o de blocos ao acaso, em esquema fatorial $5 \times 2$ com quatro repetições, caracterizado por cinco diferentes espaçamentos entrelinhas (0,40; 0,45; 0,50; 0,55 e 0,60 m) e dois cultivares de soja (P99R01 e M-Soy 9144RR). Foi avaliada a altura de plantas, número de vagens por planta, peso de mil grãos, número de plantas de U. ruziziensis aos 7, 14 e 21 dias após a emergência (DAE), índice de fechamento de linhas (IFL), radiação fotossinteticamente ativa (RFA) abaixo do dossel e RFA interceptada aos 30, 45, 60 e 75 DAE e produtividade de grãos. Independentemente do cultivar, os espaçamentos de 0,45 m a 0,50 m proporcionaram os maiores valores na altura de plantas, número de vagens por planta, número de plantas de U. ruziziensis e produtividade de grãos. Não houve efeito sobre o peso de mil grãos. Independentemente do cultivar, espaçamentos abaixo de 0,50 m proporcionaram os maiores IFL, maior interceptação da RFA e menor incidência da RFA abaixo do dossel.

Palavras-chave: Glycine max, plantas de cobertura, produtividade, radiação fotossinteticamente ativa.

\section{Initial development of Urochloa ruziziensis and agronomic performance of soybean in different space arrangements in the cerrado of Mato Grosso, Brazil}

\begin{abstract}
The consolidation of the no-tillage system in the Cerrado still faces difficulties regarding the establishment of cover crops. In this sense, has chosen by the technique of oversown aiming to take advantage of the moisture at the end of the rainy season. However, there is not always successful the establishing of the crops with this sowing system. Thus, the aim of this study was to evaluate the initial development of Urochloa ruziziensis in oversown on stage R5.3 and agronomic performance of soybean under different spacing between the lines of cultivation. The field experiment was carried out in the Barra do Garças (MT) Brazil, in 2010/2011 crop season. The experimental design was randomized blocks in a 5x2 factorial arrangement with four replications, characterized by five different row spacings (0.40; 0.45; 0.50; 0.55 and $0.60 \mathrm{~m}$ ) and two soybean cultivars (P99R01 and M-Soy 9144RR). We evaluated the plant height, number of pods plant ${ }^{-1}$, thousand grain weight, number of plants of U. ruziziensis at 7 , 14 and 21 days after emergence (DAE), index of closing of lines (ICL), photosynthetically active radiation (PAR) below the canopy and PAR intercepted at 30, 45, 60 and 75 DAE and the yield of grain. Regardless of cultivar, the spacings of $0.45 \mathrm{~m}$ to $0.50 \mathrm{~m}$ yielded the highest values in plant height, number of pods plant ${ }^{-1}$, number of plants of $U$. ruziziensis and yield of grain. There was no effect on weight of thousand grains. Regardless of cultivar, row spacing below of 0.50 m provide higher IFL, higher PAR interception and a lower incidence of PAR below the canopy.
\end{abstract}

Key words: Glycine max, cover crops, productivity, photosynthetically active radiation. 


\section{INTRODUÇÃO}

A cultura da soja tem papel de destaque no cenário de produção de grãos do Brasil, ocupando aproximadamente $53 \%$ da área total cultivada com grãos (CONAB, 2012). A regiáo do cerrado contribui significativamente para a manutenção e aumento da área cultivada com esta oleaginosa, que segundo, Oliveira Júnior et al., (2008) se deve principalmente às condiçốes topográficas favoráveis.

A soja na regiáo do cerrado tem sido cultivada com elevado nível tecnológico, entretanto, alguns aspectos têm dificultado o manejo dessa cultura, principalmente quanto à adoção de sistemas de manejo que proporcionam a manutenção dos estoques de matéria orgânica do solo (MOS). Por se tratar, de uma região que apresenta em sua maioria solos naturalmente de baixa fertilidade (WaTANABE et al., 2005), o manejo do solo se torna ferramenta indispensável para o sucesso da prática agrícola nesse bioma. Tal fato, ganha importância à medida que, nessa região a taxa de mineralização da MOS atinge altos níveis na decomposição desses resíduos, em razão da elevada temperatura e atividade microbiológica, reduzindo a quantidade desses compostos no solo (Torres et al., 2005).

Nesse sentido, a adoção do sistema de plantio direto (SPD) tem proporcionado a manutenção dos estoques de carbono no solo (Prior et al., 2004) e consequentemente melhorando os atributos químicos (Henrichs et al., 2005), físicos (Moreira et al., 2009) e biológicos do solo (Silva et al., 2007). Esse sistema que tem como premissa básica a rotação de culturas, não revolvimento do solo e o uso de plantas de cobertura, tem nesse último, uma das dificuldades para a consolidação do SPD em muitas áreas de cultivo no cerrado.

De acordo com PACHeco et al. (2008), em função da distribuição irregular e limitação na disponibilidade hídrica no cerrado, o estabelecimento de espécies visando a manutenção de palhada principalmente na entressafra, tem sido entrave em algumas regiōes. Diante disso, têm-se difundido a prática da sobressemeadura visando à formação de palhada em sucessáo à cultura da soja, no qual se trata de uma tecnologia de implantaçáo da cultura de cobertura normalmente realizada na maturação fisiológica da cultura principal (PACHECO et al., 2008) visando o aproveitamento da umidade do solo no fim do período chuvoso.

Nesse sentido, tem se buscado o cultivo de espécies que apresentam elevada capacidade de produçáo de fitomassa em condiçôes de déficit hídrico (CRUsciol et al., 2005; Petter et al., 2013). Dentre as espécies utilizadas para a formação de palhada na entressafra destaca-se a Urochloa ruziziensis que, segundo PaCheco et al., (2011), apesar do baixo desenvolvimento inicial apresenta boa capacidade de rebrota e ganhos expressivos de fitomassa seca no final da entressafra.

O sucesso da prática da sobressemeadura de plantas de cobertura, principalmente de gramíneas, depende, dentre outros fatores, das condiçôes de luminosidade durante os períodos iniciais de desenvolvimento. Por se tratarem de plantas que apresentam metabolismo C4 de fixação de $\mathrm{CO}_{2}$, a luminosidade pode ser fator limitante para sobressemeadura em estágios anteriores à maturação fisiológica da cultura principal, como exemplo, em estágio fenológico R5.3 na cultura da soja.

Diante disso, e da recente prática de alguns produtores em realizar plantios em diferentes espaçamentos e densidades de cultivo, objetivou-se com este trabalho avaliar o desempenho agronômico da soja e o desenvolvimento inicial de $U$. ruziziensis implantada em sistema de sobressemeadura no estágio R5.3 da cultura da soja sob diferentes espaçamentos nas entrelinhas.

\section{MATERIAL E MÉTODOS}

O trabalho foi realizado na área experimental da Agropecuária Fazenda Brasil, município de Barra do Garças (MT) Brasil, na safra 2010/2011, em Latossolo VermelhoAmarelo distrófico (LVAd), localizada a $15^{\circ} 00^{\prime} 21^{\prime \prime} \mathrm{S}$ e $52^{\circ} 16$ '59"O, a $270 \mathrm{~m}$ de altitude.

A análise química do solo coletada na camada de 0-20 $\mathrm{cm}$ antes da instalaçáo do experimento apresentou: $\mathrm{pH}$ $\left(\mathrm{CaCl}_{2}\right)$ : 5,56; Ca: $1,67 \mathrm{cmol} \mathrm{dm}^{-3} ; \mathrm{Mg}^{\circ} 1,17 \mathrm{cmol}_{\mathrm{c}} \mathrm{dm}^{-}$ 3; Al: $0,0 \quad \mathrm{cmol}_{c} \mathrm{dm}^{-3} ; \quad \mathrm{H}+\mathrm{Al}: \quad 2,04 \mathrm{cmol}_{c} \mathrm{dm}^{-3}$; $\mathrm{K}: 47,0 \mathrm{mg} \mathrm{dm}^{-3} ; \mathrm{P}: 3,75$; capacidade de troca catiônica: $5,43 \mathrm{cmol}_{\mathrm{c}} \mathrm{dm}^{-3} ; \mathrm{V}(\%): 54,4$; matéria orgânica: $14,78 \mathrm{~g} \mathrm{~kg}^{-1}$. A análise textural apresentou $310 \mathrm{~g} \mathrm{~kg}^{-1} \mathrm{de}$ areia, $540 \mathrm{~g} \mathrm{~kg}^{-1}$ argila e $150 \mathrm{~g} \mathrm{~kg}^{-1}$ de silte. O clima da região é o Aw segundo a classificação climática global de Köppen. Os dados de precipitação e temperatura estão apresentados na figura 1 .

O delineamento experimental utilizado foi o de blocos casualizados em esquema fatorial $5 \times 2$ com quatro repetiçôes, caracterizado por cinco diferentes espaçamentos nas entrelinhas $(0,40 ; 0,45 ; 0,50 ; 0,55$ e $0,60 \mathrm{~m})$ e dois cultivares de soja (P99R01 e M-Soy 9144RR). Não obstante o experimento ser delineado em forma de fatorial $5 \times 2$, não

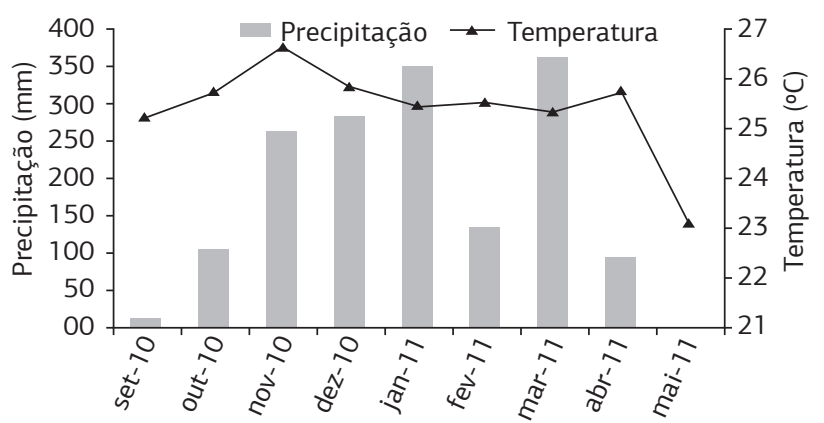

Figura 1. Precipitação mensal e temperatura média, no período de condução experimental em Barra do Garças (MT) Brasil, safra 2010/2011. 
se objetivou comparar os cultivares entre si, uma vez que as características avaliadas estão relacionados aos fatores intrínsecos (genéticos) dos materiais. O resumo dos tratamentos encontra-se na tabela 1 .

A semeadura da soja foi realizada no dia 28 de novembro de 2010 com os espaçamentos de 0,4; 0,45; 0,5; 0,55 e $0,6 \mathrm{~m}$ entrelinhas. Antes da semeadura da soja, realizou-se a adubação potássica com $96 \mathrm{~kg} \mathrm{ha}^{-1}$ de $\mathrm{K}_{2} \mathrm{O}$ a lanço, e, por ocasião da semeadura aplicou-se $250 \mathrm{~kg} \mathrm{ha}^{-1}$ da fórmula 00-36-00 (N- $\left.\mathrm{P}_{2} \mathrm{O}_{5}-\mathrm{K}_{2} \mathrm{O}\right)$.

$\mathrm{O}$ estande de plantas foi igual para todos os tratamentos, variando apenas o número de plantas por metro linear, adequados aos diferentes espaçamentos. As parcelas foram constituídas de $4 \times 5 \mathrm{~m}\left(20 \mathrm{~m}^{2}\right)$, sendo que para as avaliaçóes foi descartado $0,5 \mathrm{~m}$ de cada lado da parcela totalizando uma área útil de $12 \mathrm{~m}^{2}$.

Avaliou-se, na cultura da soja, a altura de plantas, medindo dez plantas por parcelas de forma aleatória aos 60 DAE, número de vagens por planta contabilizando cinco plantas por parcelas, peso de mil sementes (PMS) e produtividade em $\mathrm{kg} \mathrm{ha}^{-1}$ padronizada a $13 \%$ de umidade. Aos 15, 30, 45 e 60 DAE da cultura avaliou-se o índice de fechamento das entrelinhas (\%), através da escala de notas, em que $0 \%$ significa nenhuma cobertura da entrelinha e $100 \%$, entrelinha totalmente coberta.

Aos 30, 45, 60 e 75 DAE, avaliou-se a radiação fotossinteticamente ativa, com o uso de "ceptômetro" AccuPAR PAR/LAI Ceptometer model LP-80 (DECAGON Devices) em três pontos por parcela entre às 10 e 14 horas sob céu claro, medindo-se a intensidade luminosa acima do dossel e ao nível do solo. Optou-se por mediçóes nesse horário visando a reduçáo da interferência do ângulo zenital. $\mathrm{O}$ aparelho foi colocado perpendicularmente à linha de plantio formando um ângulo de $45^{\circ}$.

No estádio de desenvolvimento reprodutivo R5.3 (60 DAE) foi realizada a lanço a sobressemeadura da U. ruziziensis utilizando 600 pontos de valor cultural (CV),

Tabela 1. Resumo dos tratamentos realizados no experimento, safra 2010/2011. Barra do Garças (MT), Brasil

\begin{tabular}{|lcccc|} 
Variedade & $\begin{array}{c}\text { Espaçamento } \\
(\mathbf{m})\end{array}$ & $\begin{array}{c}\text { *No }^{\mathbf{N}} \\
\text { plantas } \\
\mathbf{h a}^{-1}\end{array}$ & $\begin{array}{c}\mathbf{N}^{\circ} \text { plantas } \\
\left(\mathbf{2 0} \mathbf{~ m} \mathbf{2}^{\mathbf{- 1}}\right.\end{array}$ & $\begin{array}{c}\mathbf{N}^{\circ} \\
\text { plantas } \\
\mathbf{m}^{-1}\end{array}$ \\
\hline M-Soy 9144 RR & 0,40 & 300.000 & 600 & 12 \\
\hline M-Soy 9144 RR & 0,45 & 300.000 & 600 & 13 \\
\hline M-Soy 9144 RR & 0,50 & 300.000 & 600 & 15 \\
\hline M-Soy 9144 RR & 0,55 & 300.000 & 600 & 16 \\
\hline M-Soy 9144 RR & 0,60 & 300.000 & 600 & 18 \\
\hline P99R01 & 0,40 & 270.000 & 540 & 11 \\
\hline P99R01 & 0,45 & 270.000 & 540 & 12 \\
\hline P99R01 & 0,50 & 270.000 & 540 & 13 \\
\hline P99R01 & 0,55 & 270.000 & 540 & 15 \\
\hline P99R01 & 0,60 & 270.000 & 540 & 16 \\
\hline
\end{tabular}

* Densidades de plantas de cada cultivar recomendado para a regiấo em estudo. com 40\% de VC. Aos 7, 14 e 21 DAE avaliou-se o número de plantas $\mathrm{m}^{-2}$ de U. ruziziensis. Optou por avaliaçóes até os $21 \mathrm{DAE}$, pois após esse período as plantas já apresentam condições a campo de se estabelecerem.

Os dados foram submetidos à análise de variância, sendo as médias das variáveis significativas comparadas pelo teste Tukey $(\mathrm{p}<0,05)$ utilizando o programa estatístico Sisvar (Ferreira, 2000). Também se realizou análise de regressão associando os coeficientes de correlação $(p<0,05)$ e determinação a cada modelo, utilizando o software SigmaPlot.

\section{RESULTADOS E DISCUSSÃO}

Independentemente do cultivar, a altura das plantas foi significativamente influenciada pelos espaçamentos nas entrelinhas e com comportamento semelhante, em que, as equaçôes de regressão se ajustaram ao modelo quadrático das curvas, evidenciando os maiores valores no espaçamento de $0,45 \mathrm{~m}$ (Figura 2a). Verifica-se um decréscimo acentuado na altura de plantas com o aumento do espaçamento nas entrelinhas acima de $0,5 \mathrm{~m}$. Esses resultados corroboram os obtidos por Mattioni et al. (2008), que observaram maiores valores de altura de plantas de soja em espaçamentos de 0,4 e $0,5 \mathrm{~m}$.

$\mathrm{O}$ número de vagens por planta foi significativamente influenciado pelos espaçamentos nas entrelinhas em ambos os cultivares testados, com destaque para o espaçamento de $0,5 \mathrm{~m}$ que proporcionou significativamente $(\mathrm{p}<0,05)$ os maiores valores para esse parâmetro comparado aos demais espaçamentos (Figura 2b). Resultados semelhantes foram obtidos por KNEBEL et al. (2006), que de maneira geral, verificaram maior número de vagens por planta com espaçamentos próximos a $0,5 \mathrm{~m}$. Já TouRINo et al. (2002) não verificaram efeito dos espaçamento entrelinhas sobre essa variável.

Não houve efeito significativo do espaçamento nas entrelinhas no peso de mil sementes, independentemente do cultivar avaliado (Figura 2c). Efeito significativo $(\mathrm{p}<0,05)$ foi verificado apenas entre os cultivares, o que pode ser atribuído à característica intrínseca do material, uma vez que, os informes agronômicos dos cultivares já apontavam para um maior peso de mil sementes do cultivar M-Soy 9144RR. Resultados semelhantes foram verificados por Mattioni et al. (2008) e Mauad et al. (2010), que não observaram efeito do espaçamento na entrelinhas de soja no peso de mil sementes.

De acordo com Rambo et al. (2003), o peso de grãos tem controle genético substancial, o que confere pouca variabilidade em funçáo do manejo cultural. Entretanto, alguns autores (Thomas et al., 1998; Pires et al., 1998) tem verificado efeito no peso de grãos em função do espaçamento na entrelinhas. Esses resultados divergentes apontam para um possível efeito das condiçóes edafoclimáticas nos componentes de rendimento na cultura da soja. De acordo com Petter et al. (2012), as condiçóes edafoclimáticas interferem na respostas da cultura da soja quanto 

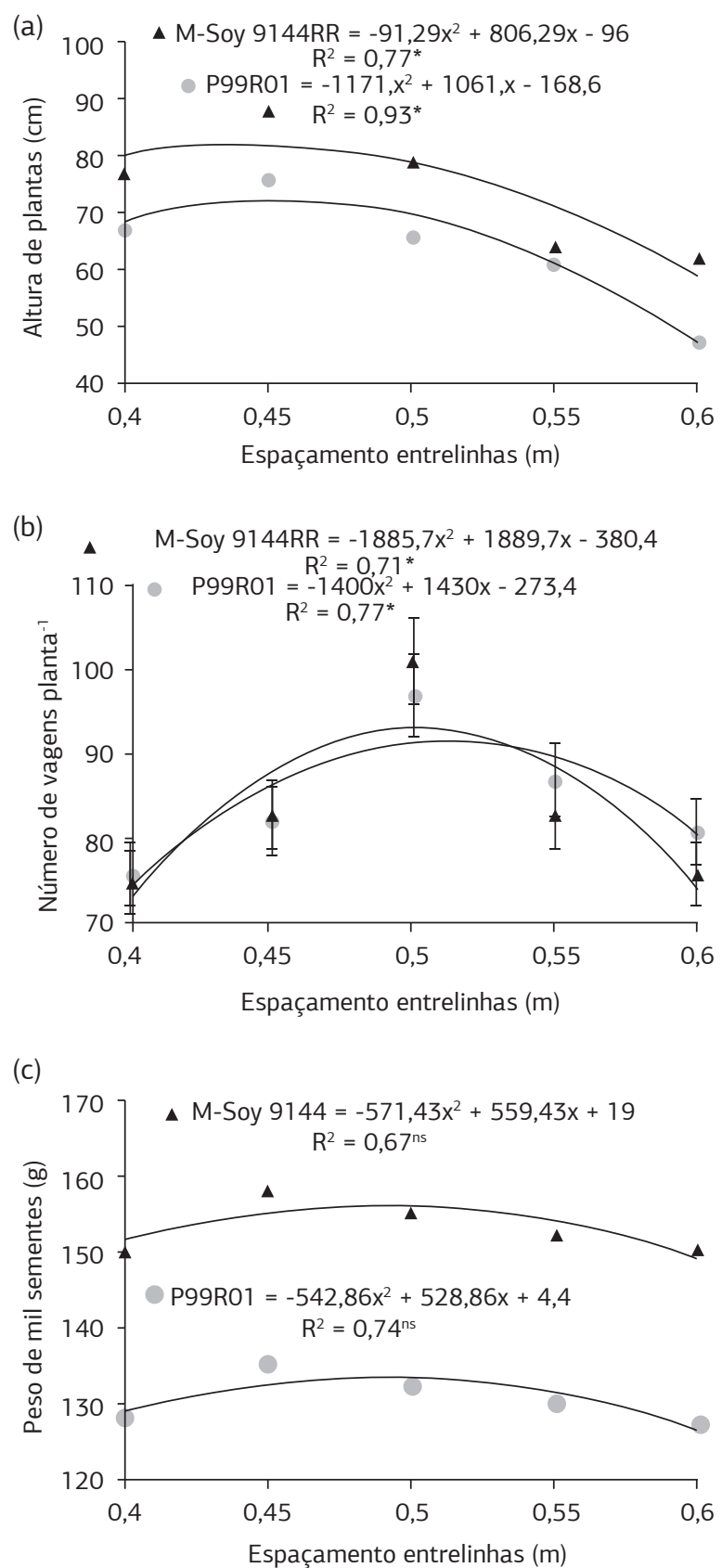

Figura 2. Altura de plantas aos 60 dias após a emergência (a), número de vagens por planta (b) e peso de mil sementes (c) de cultivares de soja M-Soy 9144RR e P99R01, sob diferentes espaçamentos da entrelinha de cultivo, em Barra do Garças (MT), safra 2010/2011. ${ }^{*}$ significativo a $5 \%$ de probabilidade.

ao manejo adotados, refletindo nos componentes de rendimento e produtividade.

O número de plantas de $U$. ruziziensis foi significativamente influenciado pelos espaçamentos nas entrelinhas de soja, em ambos os cultivares, com destaque para os espaçamentos de 0,45 e $0,5 \mathrm{~m}$ que proporcionaram melhor desenvolvimento inicial de $U$. ruziziensis independente da época de avaliação (Tabela 2). Notadamente, é visível o melhor desenvolvimento inicial de $U$. ruziziensis em espaçamentos intermediários, com valores de $30 \%$ a $50 \%$ maiores para o número de plantas, comparado aos menores e maiores espaçamento respectivamente. Esses resultados corroboram os obtidos por Pacheco et al. (2008), que também verificaram valores de número de plantas por $\mathrm{m}^{2}$ superior a $10 \mathrm{em}$ espaçamento de $0,45 \mathrm{~m}$. Os valores do número de plantas do presente estudo são superiores aos reportados por KLUTHCOUSKI e Aidar (2003), que recomendam o mínimo de 6 plantas por $\mathrm{m}^{2}$ das espécies de braquiárias para o estabelecimento como plantas de cobertura na regiáo do cerrado.

Os menores valores do número de plantas verificados nos menores $(0,4 \mathrm{~m})$ e maiores $(>0,5 \mathrm{~m})$ espaçamentos estáo, provavelmente, relacionados à intensidade da radiaçáo que chegou à parte inferior do dossel. No espaçamento de $0,4 \mathrm{~m}$ houve menor incidência de luz, o que reduziu e retardou o processo de germinaçáo e desenvolvimento inicial das sementes de $U$. ruziziensis, como verificado no índice de fechamento das entrelinhas e da RFA abaixo do dossel. De acordo com Portes et al. (2000), por apresentarem metabolismo C4 de fixação de $\mathrm{CO}_{2}$, as braquiárias apresentam característica que as torna muito exigentes por luz, fator este, preponderante para o desenvolvimento inicial da cultura.

Já para os espaçamentos maiores, o menor estabelecimento e desenvolvimento inicial das plantas de $U$. ruziziensis, provavelmente está associado à maior incidência de radiação solar, o que proporcionou a ocorrência de necrose do coleóptilo e da radícula, resultando em morte das plantas. Efeito semelhante foi observado por Pacheco et al. (2008), que também verificaram crestamento do coleóptilo e radícula em plântulas decorrente da intensa radiação solar em estágios iniciais de desenvolvimento.

$\mathrm{O}$ índice de fechamento das entrelinhas foi significativamente $(\mathrm{p}<0,05)$ influenciado pelos espaçamentos de cultivo (Figuras $3 \mathrm{a}$ e b). Independentemente do cultivar, verifica- se que os espaçamentos abaixo de $0,5 \mathrm{~m}$ proporcionaram fechamento médio da entre linha superior a $85 \%$ aos $60 \%$ $\mathrm{DAE}$, enquanto que, em espaçamentos maiores, esse valor foi inferior a $70 \%$. Resultados semelhantes foram obtidos por Heiffig et al. (2006), que verificaram fechamento da entrelinha abaixo de $75 \%$ com densidade de plantas próximas ao do presente estudo. As maiores diferenças foram verificadas aos 45 DAE no cultivar P99R01, em que, os maiores espaçamentos na entrelinha proporcionaram fechamento médio abaixo de $50 \%$, enquanto que em espaçamentos abaixo de $0,5 \mathrm{~m}$ apresentaram fechamento da entrelinha superior a $80 \%$.

A maior porcentagem de fechamento da entrelinha pode auxiliar o controle das plantas daninhas e no melhor aproveitamento da RFA. Todavia, altos índices de fechamento e de forma precoce, que é o que se observa na maioria das vezes em espaçamentos muito reduzidos $(<0,4 \mathrm{~m})$ e sem a compensaçáo da densidade de plantas, podem acarretar autossombreamento das folhas do terço inferior e redução da circulação de ar na entrelinha, proporcionando assim, menor eficiência no uso da RFA e microclima favorável ao desenvolvimento de algumas doenças, respectivamente. 
Tabela 2. Número de plantas de Urochloa ruziziensis em função de diferentes espaçamentos na entrelinha de cultivo de dois cultivares de soja, safra 2010/2011. Barra do Garças (MT)

\begin{tabular}{|c|c|c|c|c|c|c|}
\hline \multirow{4}{*}{$\begin{array}{l}\text { Espaçamento } \\
\text { entrelinhas } \\
\text { (m) }\end{array}$} & \multicolumn{6}{|c|}{ Número de plantas $\mathrm{m}^{2}$} \\
\hline & \multirow{2}{*}{\multicolumn{3}{|c|}{$\begin{array}{c}\text { M-Soy 9144RR } \\
\text { Dias após a } \\
\text { emergência }\end{array}$}} & \multirow{2}{*}{\multicolumn{3}{|c|}{$\begin{array}{c}\text { P99R01 } \\
\text { Dias após a } \\
\text { emergência }\end{array}$}} \\
\hline & & & & & & \\
\hline & 7 & 14 & 21 & 7 & 14 & 21 \\
\hline 0,40 & $3,5^{b}$ & $6,0^{b, c}$ & $9,12^{\mathrm{a}, \mathrm{b}}$ & $3,00^{b}$ & $5,75^{c}$ & $8,50^{\mathrm{b}}$ \\
\hline 0,45 & $9,5^{\mathrm{a}}$ & $10,5^{a}$ & $12,0^{\mathrm{a}}$ & $7,25^{a}$ & $9,25^{\mathrm{a}, \mathrm{b}}$ & $12,75^{a}$ \\
\hline 0,50 & $2,75^{b}$ & $8,0^{\mathrm{a}, \mathrm{b}}$ & $13,5^{\mathrm{a}}$ & $2,75^{b}$ & $9,50^{\mathrm{a}}$ & $12,75^{a}$ \\
\hline 0,55 & $1,25^{b}$ & $3,25^{c}$ & $6,0^{\mathrm{b}}$ & $1,00^{b}$ & $5,25^{c}$ & $8,50^{\mathrm{b}}$ \\
\hline 0,60 & $1,25^{\mathrm{b}}$ & $5,0^{\mathrm{b}, \mathrm{c}}$ & $5,50^{b}$ & $0,75^{b}$ & $6,50^{\mathrm{b}, \mathrm{c}}$ & $9,25^{\mathrm{b}}$ \\
\hline CV\% & 22,5 & 22,1 & 32 & 12,20 & 12,50 & 15,34 \\
\hline
\end{tabular}

As médias seguidas pela mesma letra nâo diferem entre si $(\mathrm{p}<0,05)$ pelo teste de Tukey.

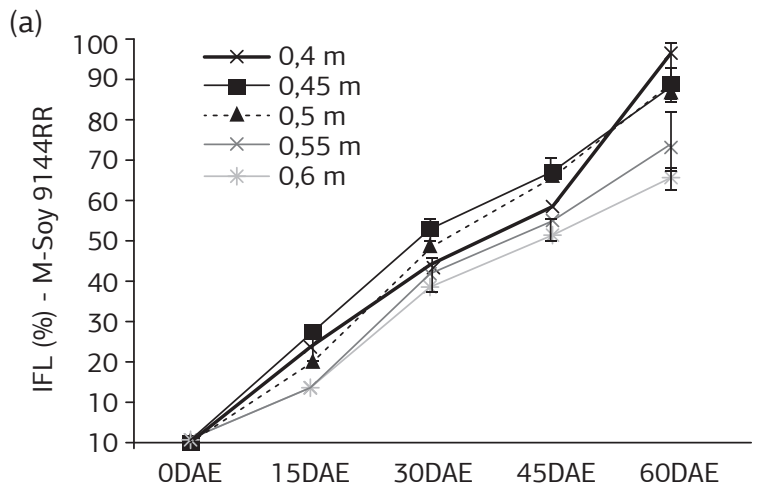

(b)

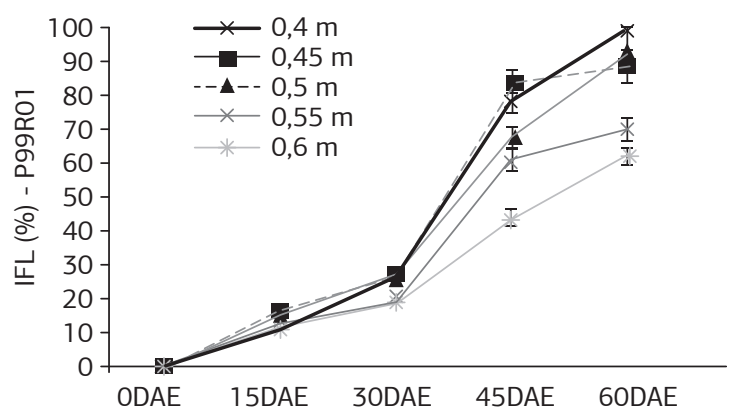

Figura 3. Índice de fechamento das entrelinhas (IFL) de soja cultivar M-Soy 9144RR (a) e P99R01 (b) sob diferentes espaçamentos de cultivo com respectivo desvio-padrão, em Barra do Garças (MT), safra 2010/2011. IFL: índice de fechamento das entrelinhas; DAE: dias após a emergência.

A produtividade da soja foi significativamente influenciada pelos espaçamentos nas entrelinhas, com destaque para os espaçamentos de 0,45 e $0,5 \mathrm{~m}$ (Figura 4). A máxima produtividade ou eficiência técnica foi de 3.538 e $3.365 \mathrm{~kg} \mathrm{ha}^{-1}$ com espaçamentos estimados de $0,48 \mathrm{e}$ 0,49 m para os cultivares M-Soy 9144RR e P99R01, respectivamente. Heiffig et al. (2006) também verificaram comportamento semelhante na produtividade, em que, constataram aumento do menor espaçamento $(0,2 \mathrm{~m})$ para os espaçamentos intermediários $(0,4$ e $0,5 \mathrm{~m})$ e

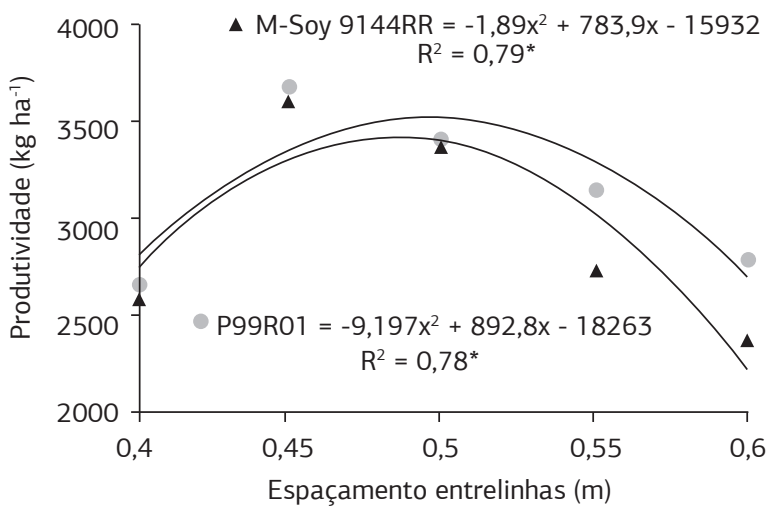

Figura 4. Produtividade de cultivares de soja M-Soy 9144RR e P99R01 sob diferentes espaçamentos na entrelinha de cultivo, em Barra do Garças (MT), safra 2010/2011. * significativo a 5\% de probabilidade.

decréscimos nos espaçamentos acima de 0,6 $\mathrm{m}$. Do mesmo modo, Mattioni et al. (2008) e Komatsu et al. (2010) em trabalhos com densidade de plantas semelhantes ao do presente estudo, verificaram maior produtividade de grãos em espaçamentos de $0,45 \mathrm{~m}$ comparado à espaçamentos maiores e menores, respectivamente.

As menores produtividades observadas nos menores espaçamentos pode estar relacionada com a maior competição intraespecífica pelos fatores ambientais. Outro aspecto a ser considerado é o fato de que em menores espaçamentos há um maior autossombreamento principalmente das folhas inferiores, como se verifica nos dados de índice de fechamento das entre linhas (Figuras 3a,b) e da menor radiação fotossinteticamente ativa (RFA) incidente abaixo do dossel.

Já, em espaçamentos maiores, a redução da produtividade pode estar associada não só, à maior competiçáo intraespecífica em função do aumento no número de plantas ao longo da linha de plantio, mas também, ao menor índice de área foliar e consequentemente menor interceptação da RFA. Em espaçamentos intermediários, há uma melhor distribuição equidistante e espacial do sistema radicular e parte aérea das plantas, o que favorece o melhor aproveitamento dos recursos do ambiente como água, luz e nutrientes. Segundo KnEBel et al. (2006), nessas condições as plantas apresentam um crescimento mais harmônico, não necessitando, por exemplo, de alongar o caule em busca de luminosidade, reduzindo assim, o acamamento e autossombreamento.

Os maiores espaçamentos na entrelinha de cultivo proporcionaram maiores valores de RFA abaixo do dossel independente do cultivar avaliado (Figuras 5a-c). Observa-se que os valores de RFA incidente abaixo do dossel (solo) no período de 15 dias após a sobressemeadura de $U$. ruziziensis no espaçamento de $0,6 \mathrm{~m}$ foi de aproximadamente 3,4 e 2,7 vezes superior comparado ao espaçamento de $0,40 \mathrm{~m}$ para os cultivares M-Soy 9144RR e P99R01, respectivamente. Tal fato reforça a hipótese do efeito deletério 
reportado anteriormente da incidência de radiação solar sobre o coleóptilo e radícula das plantas, uma vez que, as mesmas foram semeadas sobre a superfície do solo, ou seja, sem a incorporação ao solo.

Independemente do cultivar avaliado, a RFA interceptada foi significativamente influenciada pelos espaçamentos nas entrelinhas (Figura 5b-d). Os maiores valores (-95\%) de interceptação da RFA foram verificados nos espaçamentos de 0,4 a $0,5 \mathrm{~m}$ em ambos os cultivares. Esses dados assemelham-se aos obtidos por Souza et al. (2008) e Fontana et al. (2012), que verificaram $95 \%$ e $90 \%$ de interceptação da RFA em espaçamento de entrelinhas de cultivo de 0,45 e $0,4 \mathrm{~m}$, respectivamente.

Enquanto que, nos espaçamentos menores $(0,4 \mathrm{a}$ $0,5 \mathrm{~m})$ nas entrelinhas foi interceptada aproximadamente 95\% da RFA incidente no topo do dossel, no espaçamento de $0,6 \mathrm{~m}$ a interceptação foi de apenas $82 \%$. Isso explica em parte os menores valores de produtividade observados nos tratamentos com espaçamentos de 0,6 m. Dados da literatura demonstram que o arranjo de plantas associado a um índice de área foliar que permite a interceptação de pelo menos $90 \%$ da RFA é altamente desejável e interferem significativamente na produtividade.

Importante ressaltar, que o modelo que melhor se ajustou à curva de produtividade se comportou de maneira quadrática, evidenciando que no menor espaçamento também houve redução na produtividade. Tal comportamento pode estar associado à distribuição da RFA ao longo do dossel, ou seja, apesar de maior interceptação da RFA, esta pode ter sido restrita a camadas superiores, limitando assim, a luminosidade nas folhas do terço inferior das plantas.

Essa característica pode ser explicada pelo coeficiente de extinção luminosa, pois de acordo com Procópio et al. (2003), este fornece indicaçóes sobre a eficiência das (a)

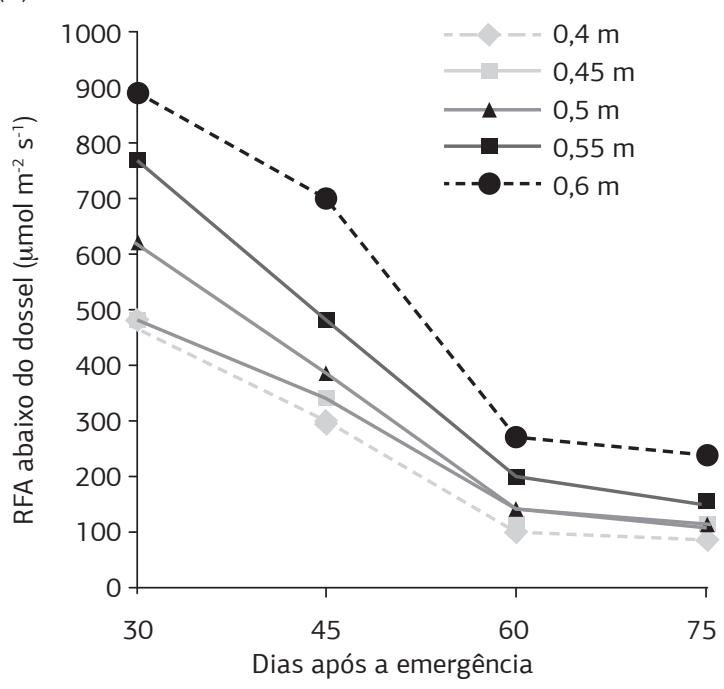

(b)

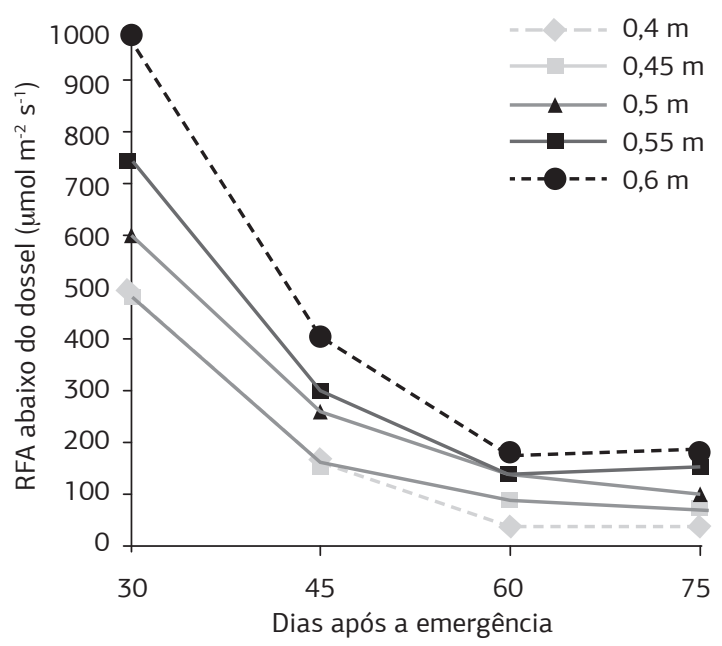

(c)

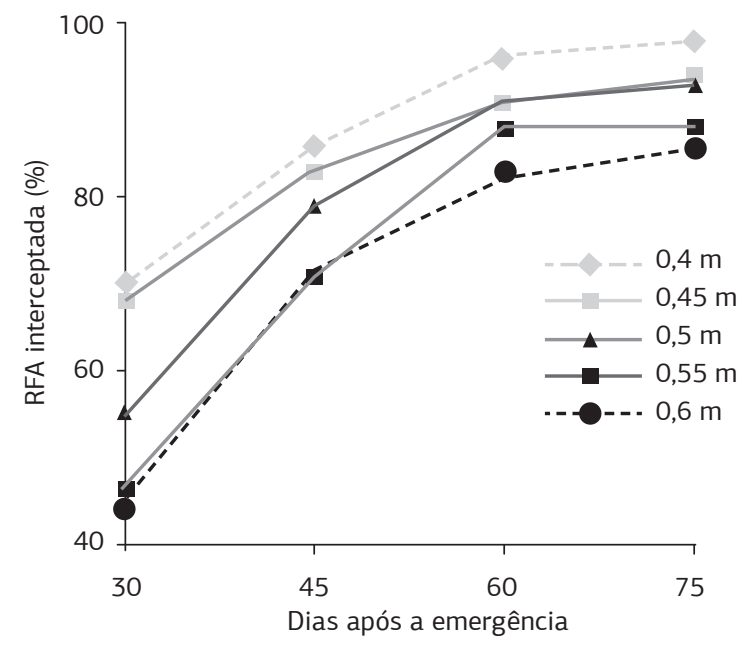

(d)

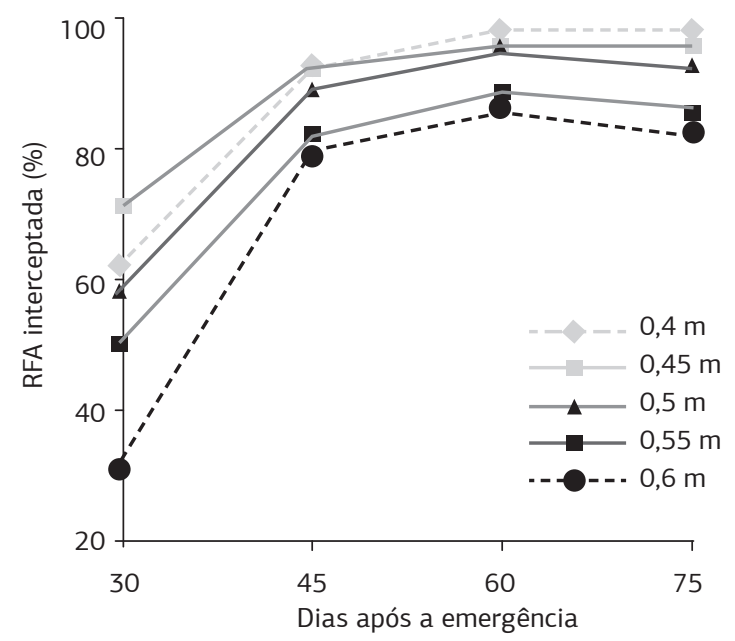

Figura 5. Radiaçóes fotossinteticamente ativas abaixo do dossel e interceptada em diferentes espaçamentos de entrelinhas nos cultivares M-Soy 9144RR (a,b) e P99R01 (c,d), em Barra do Garças (MT), safra 2010/2011. 
plantas em interceptar a radiação, interferindo na estimativa de produçáo de fitomassa e produtividade das culturas. De acordo com Schöffel e Volpe (2001), a quantidade de energia luminosa e a transmissão da RFA é uma função exponencial negativa do produto do índice de área foliar (IAF) pelo coeficiente de extinção (k), ou seja, a quantidade de luz que penetra ao longo dossel reduz de maneira exponencial à medida que há aumento do índice de área foliar.

Os resultados apontam para um comportamento semelhante dos cultivares de soja quanto à resposta ao espaçamento na entrelinha de cultivo. Como já evidenciado em diversos trabalhos, espaçamentos de 0,45 a $0,5 \mathrm{~m}$ parecem proporcionar os maiores rendimentos da cultura da soja na região do cerrado. Entretanto, a maior parte dos trabalhos envolvendo diferentes espaçamentos nas entrelinhas de cultivo também avaliaram as variaçôes nas densidades de plantas $\mathrm{ha}^{-1}$, o que proporcionou resultados satisfatórios em alguns trabalhos em espaçamentos abaixo de 0,4 m.

Diante disso, este estudo permite destacar que o manejo do espaçamento na entrelinha deve ser tratado com cautela em condições que não há variação da densidade populacional de plantas, ou seja, em condições em que não há uma compensação da distribuição espacial das plantas na área. Esses resultados são importantes para o manejo da cultura da soja associado à técnica de sobressemeadura de plantas de cobertura, principalmente com a recente prática de alguns agricultores em realizar a técnica de plantio cruzado, o que ainda não está atestado pela pesquisa.

Este estudo também permite destacar a técnica de sobressemeadura em estágios anteriores (R5.3) à maturaçáo fisiológica da cultura principal como uma alternativa para o melhor aproveitamento da umidade do solo no final do período chuvoso.

\section{CONCLUSÃO}

Os espaçamentos de 0,45 a $0,5 \mathrm{~m}$ proporcionam os melhores resultados de desempenho agronômico da soja e no desenvolvimento inicial de $U$. ruziziensis semeada utilizando a técnica da sobressemeadura.

\section{REFERÊNCIAS}

COMPANHIA NACIONAL E ABASTECIMENTO (CONAB). In: Acompanhamento da safra 2012. Disponível em: <http://www. conab.gov.br/safras.asp> Acesso em: nov./2012.

CRUSCIOL, C.A.C.; COTTICA, R.L.; LIMA, E.V.; ANDREOTTI, M.; MORO, E.; MARCON, E. Persistência de palhada e liberação de nutrientes do nabo forrageiro no plantio direto. Pesquisa Agropecuária Brasileira, v.40, p.161-168, 2005. DOI: 10.1590/ S0100-204X2005000200009.

FERREIRA, D.F. SISVAR: Sistema de Análise de Variância. Lavras: UFLA, 2000. 145p.
FONTANA, D.C.; ALVES, G.M.; ROBERTI, D.; MORAES, O.L. L.; GERHARDT, A. Estimativa da radiação fotossinteticamente ativa absorvida pela cultura da soja através de dados do sensor Modis. Bragantia, v.71, p.563-571, 2012. DOI: 10.1590/S000687052012000400015 .

HEIFFIG, S.L.; CÂMARA, S.M.G.; MARQUES, A.L.; PEDROSO, B.D.; PIEDADE, S.M.S. Fechamento e índice de área foliar da cultura da soja em diferentes arranjos espaciais. Bragantia, v.65, p.285-295, 2006. DOI: 10.1590/S0006-87052006000200010.

HEINRICHS, R.; VITTI, G.C.; MOREIRA, A.; FIGUEIREDO, P.A.M.; FANCELLI, A.L.; CORAZZA, E.J. Características químicas de solo e rendimento de fitomassa de adubos verdes e de grãos de milho, decorrente do cultivo consorciado. Revista Brasileira de Ciência do Solo, v.29, p.71-79, 2005. DOI: 10.1590/S010006832005000100008 .

KLUTHCOUSKI, J.; AIDAR, H. Implantação, condução e resultados obtidos com o sistema Santa-Fé. In: KLUTHCOUSKI, J.; AIDAR, H.; STONE, L.F. Integração lavoura-pecuária. Santo Antônio de Goiás: Embrapa Arroz e Feijão, p. 407-441, 2003.

KNEBEL， J.L.; GUIMARÃES, V.F.; ANDREOTTI, M.; STANGARLIN, J.R. Influência do espaçamento e população de plantas sobre doenças de final de ciclo e oídio e caracteres agronômicos em soja. Acta Scientiarum Agronomy, v.28, p.385-392, 2006. DOI: 10.4025/actasciagron.v28i3.962.

KOMATSU, R.A.; GUADAGNIN, D.D.; BORGO, M.A. Efeito do espaçamento de plantas sobre o comportamento de cultivares de soja de crescimento determinado. Campo Digital, v.5, p.50-55, 2010.

MATTIONI, F.; CORRÊA, L.A.V.; GOMES, J.C.C.; WÜNCH, J. Arranjos espaciais, plantas concorrentes e características agronômicas da soja (Glycine max (Linn) Merril) em cultivo orgânico. Revista Brasileira de Agrociência, v.14, p.21-32, 2008.

MAUAD, M.; SILVA, T.L.B.; ALMEIDA NETO, A.I.; ABREU, V.G. Influência da densidade de semeadura sobre características agronômicas na cultura da soja. Agrarian, v.3, p.175-181, 2010.

MOREIRA, J.A.A.; AGUIAR, R.A.; STONE, L.F; BERNARDES, T.G.; PEREIRA FILHO, I.A.; CRUZ, J.C. Efeito de diferentes plantas de cobertura do solo sobre alguns atributos do solo em sistema de produção orgânico. Revista Brasileira de Agroecologia, v.4, p.3748-3751, 2009.

OLIVEIRA JUNIOR, A.; PROCHNOW, L.I; KLEPKER, D. Eficiência agronômica de fosfato natural reativo na cultura da soja. Pesquisa Agropecuária Brasileira, v.43, p.623-631, 2008. DOI: 10.1590/S0100-204X2008000500010.

PACHECO, L.P.; PIRES, F.R.; MONTEITO, F.P.; PROCÓPIO, S.O.; ASSIS, R.L.; CARMO, M.L. PETTER, F.A. Desempenho de plantas de cobertura em sobressemeadura na cultura da soja. Pesquisa Agropecuária Brasileira, v.43, p.815-823, 2008. DOI: 10.1590/ S0100-204X2008000700005.

PACHECO, L.P.; LEANDRO, W.M.; MACHADO, P.O.A.; ASSIS, R.L.; COBUCCI, T.; MADARI, B.E.; PETTER, F.A. Produção de fitomassa e acúmulo e liberação de nutrientes por plantas de cobertura na safrinha. Pesquisa Agropecuária Brasileira, v.46, p.1725, 2011. DOI: 10.1590/S0100-204X2011000100003. 
PETTER, F.A.; PACHECO, L.P.; ALCÂNTARA NETO, F.; SANTOS, G.G. Respostas de cultivares de soja à adubação nitrogenada tardia em solos de cerrado. Revista Caatinga, v.25, p.6772, 2012 .

PETTER, F.A; PACHECO, L.P.; ZUFFO, A.M.; PIAUILINO, A.C.; XAVIER, Z.F.; SANTOS, J.M.; MIRANDA, J.M.S. Desempenho de plantas de cobertura submetidas à déficit hídrico. Semina, v.34, p.1331-1339, 2013.

PIRES, J.L.F.; COSTA, J.A.; THOMAS, A.L. Rendimento de grãos de soja influenciado pelo arranjo de plantas e níveis de adubaçáo. Pesquisa Agropecuária Gaúcha, v.4, p.89-92, 1998.

PORTES, T.A.; CARVALHO, S.I.C.; OLIVEIRA, I.P.; KLUTHCOUSKI, J. Análise do crescimento de uma cultivar de braquiária em cultivo solteiro e consorciado com cereais. Pesquisa Agropecuária Brasileira, v.35, p.1349-1358, 2000. DOI: 10.1590/ S0100-204X2000000700009.

PRIOR, S.A.; TORBERT, H.A.; RUNION, G.B.; ROGERS, H. Elevated atmospheric $\mathrm{CO}_{2}$ in Agroecosystems: Residue decomposition in the field. Environmental Management, v.33, suplemento, p.344354, 2004. DOI: 10.1007/s00267-003-9143-0.

PROCÓPIO, S.O.; SANTOS, J.B.; SILVA, A.A.; COSTA, L.C. Desenvolvimento foliar das culturas da soja e do feijão e de plantas daninhas. Ciência Rural, v.33, p.207-211, 2003. DOI: 10.1590/ S0103-84782003000200005.

RAMBO, L.; COSTA, J.A.; PIRES, J.L.P.; PARCIANELLO, G.; FERREIRA, F. G. Rendimento de grãos da soja em função do arranjo de plantas. Ciência Rural, v.33, p.405-411, 2003. DOI: 10.1590/ S0103-84782003000300003.
SCHÖFFEL, E.R.; VOLPE, C.A. Eficiência de conversão da radiação fotossinteticamente ativa interceptada pela soja para a produção de fitomassa. Revista Brasileira de Agrometeorologia, v.9, p.241-249, 2001.

SILVA, M.B.; KLIEMANN, H.J.; SILVEIRA, P.M.; LANNA, A.C. Atributos biológicos do solo sob influência da cobertura vegetal e do sistema de manejo. Pesquisa Agropecuária Brasileira, v.42, p.1-7, 2007. DOI: 10.1590/S0100-204X2007001200013.

SOUZA, P.J.O.P.; RIBEIRO, A.; ROCHA, E.J.P.; LOUREIRO, R.S. BISPO, C.J.C. Uso da radiação pela soja (Glycine max (L.) Merryll), em Paragominas-PA. Revista Brasileira de Agrometeorologia, v.16, p.175-181, 2008.

THOMAS, A.L.; COSTA, J.A.; PIRES, J.L. Rendimento de grãos de soja afetado pelo espaçamento entre linhas e fertilidade do solo. Ciência Rural, v.28, p.543-546, 1998. DOI: 10.1590/S010384781998000400002 .

TORRES, J.L.R.; PEREIRA, M.G.; ANDRIOLI, I.; POLIDORO, J.C. FABIAN, A.J. Decomposição e liberação de nitrogênio de resíduos culturais de plantas de cobertura em um solo de cerrado. Revista Brasileira de Ciência do Solo, v.29, p.609-618, 2005.

TOURINO, M.C.C.; REZENDE, P.M.; SALVADOR, N. Espaçamento, densidade e uniformidade de semeadura na produtividade e características agronômicas da soja. Pesquisa Agropecuária Brasileira, v.37, p.1071-1077, 2002.

WATANABE, R.T.; FIORETTO, R.A.; FONSECA, I.B.; SEIFERT, A.L.; SANTIAGO, D.C.; CRESTE, J.E.; HARADA, A.; CUCOLOTTO, M. Produtividade da cultura da soja em função da densidade populacional e da porcentagem de cátions ( $\mathrm{Ca}, \mathrm{Mg}$ e $\mathrm{K}$ ) no complexo sortivo do solo. Semina, v.26, p.477-484, 2005. 